\title{
Fibroblast growth factor 23 and $\alpha$-Klotho serum concentration did not differ between children with autosomal dominant polycystic kidney disease and healthy controls
}

\author{
Marta Kostrzewa', Kamil W. Faltin', Monika Pawlak-Bratkowska², Piotr Grzelak \\ Alina Niewiadomska ${ }^{4}$, Marcin Tkaczyk ${ }^{2,5}$ \\ 'Department of Paediatrics, Preventive Cardiology and Immunology of Developmental Age, Student Study Group, \\ Medical University of Lodz, Lodz, Poland \\ 2Department of Paediatrics, Immunology and Nephrology, Polish Mother's Memorial Hospital Research Institute, \\ Lodz, Poland \\ ${ }^{3}$ Department of Diagnostic Imaging, Polish Mother's Memorial Hospital Research Institute, Lodz, Poland \\ ${ }^{4}$ Laboratory Diagnostics Center, Polish Mother's Memorial Hospital Research Institute, Lodz, Poland \\ ${ }^{5}$ Division of Didactics in Paediatrics, Medical University of Lodz, Lodz, Poland
}

\section{ABSTRACT}

Introduction: Autosomal dominant polycystic kidney disease (ADPKD) is the most common inherited monogenous kidney disease that can also be seen in children. One of the indicators of changes in metabolism in ADPKD children according to the novel knowledge are fibroblast growth factor 23 (FGF-23) and $\alpha$-Klotho protein.

Aim of the study: To observe whether children who suffer from ADPKD whilst preserving normal kidney function $\left(\mathrm{eGFR}>90 \mathrm{ml} / \mathrm{min} / 1.73 \mathrm{~m}^{2}\right.$ ) have any changes in the concentration of FGF-23 and Klotho protein along with the growth of renal volume.

Material and methods: The study was a cross-sectional analysis of 70 children aged from 1 to 18.8 years. FGF-23 and Klotho were measured by the ELISA tests. Clinical and laboratory analysis comprised the following: ultrasound measurement of the total kidney volume (TKV), eGFR calculation, serum calcium, phosphate, and urinary albumin excretion.

Results: Serum concentration of FGF-23 did not differ between children suffering from ADPKD and the control group ( $27.77 \mathrm{pg} / \mathrm{ml}$ vs. $24.15 \mathrm{pg} / \mathrm{ml} ; p=0.96)$. $\alpha$-Klotho concentrations were also similar $(1650 \mathrm{pg} / \mathrm{ml}$ vs. $1440 \mathrm{pg} / \mathrm{ml} ; p=0.14$ ) between both groups. Klotho correlated significantly with FGF-23 ( $R s=0.55$; $p=0.000002)$ and eGFR $(R s=0.25 ; p=0.039566)$. No significant relation was detected between FGF-23 or Klotho concentration and albumin excretion, TKV, age, or anthropometric measures.

Conclusions: FGF-23 and $\alpha$-Klotho concentration did not differ significantly between children suffering from $\mathrm{ADPKD}$ and the control group.

\section{KEY WORDS:}

ADPKD, children, FGF-23, $\alpha$-Klotho, progression.

\section{ADDRESS FOR CORRESPONDENCE:}

Marta Kostrzewa, Department of Paediatrics, Preventive Cardiology and Immunology of Developmental Age, Student Study Group, Medical University of Lodz, 4 Kościuszki Ave, 90-419 Lodz, Poland, ORCID: 0000-0002-2847-6364, e-mail: kostrzewa.marta@interia.pl 


\section{INTRODUCTION}

Autosomal dominant polycystic kidney disease (ADPKD) is the most common hereditary type of monogenic kidney disease, affecting 1 out of 400 to 1000 births [1]. ADPKD is caused by a mutation in the PKD1 or PKD2 genes (responsible for $85 \%$ and $15 \%$ of the cases of ADPKD, respectively), the products of which are polycystin 1 and 2, which act as transmembrane proteins involved in the transportation of calcium [2]. The main manifestation of ADPKD is a bilateral progressive cystic dilation of the renal tubules with an eventual compression of normal renal parenchyma, kidney enlargement, and loss of renal function. At ages between 20 and 40 years, $50 \%$ of the normal parenchyma is replaced by cysts. Fifty per cent of patients reach end-stage renal disease by the age of 60 years. An early manifestation of ADPKD includes the following: hypertension, albuminuria, proteinuria, and impaired renal function, and it occurs before the age of 15 years $[3,4]$.

One of the abnormalities that develop as kidney function declines is the disturbance of calcium and phosphate metabolism. Fibroblast growth factor 23 (FGF-23) is secreted by osteocytes and osteoblasts and regulates bone mineralisation. In the kidney, FGF-23 binds to the canonical FGF receptor in the presence of the Klotho cofactor and suppresses renal tubular phosphate reabsorption and $1 \alpha$-hydroxylase activity, which exerts effects on the bone/ kidney/parathyroid axis. In conclusion, it leads to phosphaturia and hypophosphataemia and low serum levels of 1,25 dihydroxy vitamin $\mathrm{D}[2,5,6]$. FGF-23 increases in response to serum phosphorus level increase in patients with chronic kidney disease (CKD); it occurs from early stages of CKD and helps maintain the serum phosphate level in its normal range. During the CKD progression, FGF-23 concentration increases and Klotho protein concentration decreases. However, it has not been confirmed from which stage of CKD during ADPKD in children the changes in concentration occur $[7,8]$. Decrease in glomerular filtration rate in ADPKD correlates with an increase in total kidney volume (TKV), defined as the sum volume of both kidneys $[9,10]$. It seems that the increase of FGF-23 concentration is one of the earliest biochemical markers of decreased glomerular filtration rate [11].

The aim of this study is to investigate the serum levels of FGF-23 and soluble Klotho in children with ADPKD, who retain normal renal function (eGFR $>90 \mathrm{ml} / \mathrm{min} / 1.73 \mathrm{~m}^{2}$ ), and whether those level changes depend on classic indicators of disease progression.

\section{MATERIAL AND METHODS}

The study was designed as a cross-sectional analysis amongst ADPKD children and healthy controls. The Local Ethical Committee approved the protocol. Informed consent was obtained before inclusion of each patient.

\section{STUDY GROUP}

The study was a cross-sectional analysis of 70 children (45 patients with ADPKD - 29 females and 16 males; and 25 patients comprised the healthy control group $-15 \mathrm{fe}$ males and 10 males), aged from 1 to 18.8 years (average age 10.7 years), who were recruited from Paediatric and General Nephrology Outpatient Clinics.

Clinical characteristics of the study group are described in Table 1. Patients were not hypertensive. Also, they did not receive renin-angiotensin system inhibition.

The group of ADPKD patients consisted of both children who fulfilled the ultrasound criteria of Ravine et al. for the diagnosis of disease (bilateral cysts in the kidneys, including a minimum of three cysts with diameter $\geq 10 \mathrm{~mm}$ ), as well as children who did not meet the criteria, who were diagnosed with at least one cyst and a positive family history for ADPKD. A similar method of qualification was used in the available population studies of children with ADPKD [12]. Children with significant comorbidities not related to ADPKD were excluded.

\section{METHODS}

Blood pressure and anthropometric measurements were performed in a standardised setting during routine control visits. Urine and fasting serum samples were taken in the morning. Serum for FGF-23 and Klotho was carefully centrifuged and frozen at $-80^{\circ} \mathrm{C}$ until analysis.

TKV was assessed by an ultrasound performed by an experienced physician using ProSound Alpha 7 Aloka apparatus with a convex transducer. It was calculated from the formula: $\mathrm{KV}=0.52 \times \mathrm{D} \times \mathrm{S} \times \mathrm{G}$, where: $\mathrm{KV}$ - kidney volume, D - length of the kidney $(\mathrm{cm}), \mathrm{S}$ - width of the kidney $(\mathrm{cm}), \mathrm{G}-$ kidney thickness $(\mathrm{cm})$. Total kidney volume was defined as the sum of the volume of both kidneys and was related to the patient's body surface (TKV/ BSA $\left.\left[\mathrm{cm}^{3} / \mathrm{m}^{2}\right]\right)$. The number of cysts was also calculated.

Routine biochemical analysis was performed and comprised the following: Biochemical testing, which included renal parameters, electrolytes, and parameters of calcium-phosphate metabolism by a standard laboratory procedure. Evaluation of kidney function was assessed by measuring the serum creatinine concentration $(\mathrm{mg} / \mathrm{dl})$ and creatinine clearance $\left(\mathrm{ml} / \mathrm{min} / 1.73 \mathrm{~m}^{2}\right)$. The latter was calculated using the "Bedside Schwartz" formula for children. The albumin/creatinine ratio was established from morning urine.

FGF-23 concentration levels were measured using the Human Fibroblast Growth Factor 23 Kit Elisa Kit from Wuhan EIAab Science Co. Ltd, while the Klotho protein was measured using the Cloud-Clone Corp Enzyme-linked Immunosorbent Assay Kit.

The data collected during the examination was subjected to statistical analysis. The normality of the distribution of continuous variables was assessed using the 
TABLE 1. Clinical and laboratory data in the study group and healthy controls

\begin{tabular}{|c|c|c|c|c|}
\hline Characteristic & $\begin{array}{l}\text { Total cohort } \\
n=70\end{array}$ & $\begin{array}{l}\text { ADPKD group } \\
\qquad n=45\end{array}$ & $\begin{array}{l}\text { Healthy controls } \\
\qquad n=25\end{array}$ & $p$-value \\
\hline FGF-23 (pg/ml) & $25.96(9.24-138.05)$ & $27.77(12.49-134.29)$ & $24.15(8.46-154.78)$ & 0.96 \\
\hline Klotho (pg/ml) & $1530(795-2400)$ & $1650(950-2580)$ & $1440(680-1950)$ & 0.14 \\
\hline Age (months) & $136.5(80-184)$ & $138(82-187)$ & $135(77-181)$ & 0.68 \\
\hline Body mass (kg) & $\begin{array}{c}39(20.5-58) \\
\text { SDS } 0.38\end{array}$ & $\begin{array}{c}41(22-59) \\
\text { SDS } 0.39\end{array}$ & $\begin{array}{l}37(20.5-56) \\
\text { SDS } 0.38\end{array}$ & 0.83 \\
\hline Height $(\mathrm{cm})$ & $\begin{array}{c}152.25(122-172) \\
\text { SDS } 0.83\end{array}$ & $\begin{array}{l}155.5(122-172) \\
\text { SDS } 0.82\end{array}$ & $\begin{array}{l}149(126-166.5) \\
\text { SDS } 0.86\end{array}$ & 0.67 \\
\hline $\mathrm{uACR}$ & $10.2(4.2-24.69)$ & $17.59(5.38-45.96)$ & $5.21(3.26-6.57)$ & $<0.001$ \\
\hline $\mathrm{eGFR}\left(\mathrm{ml} / \mathrm{min} / 1.73 \mathrm{~m}^{2}\right)$ & $149.5(133.65-171.05)$ & $150.1(137-171.9)$ & $140.8(114.5-160.6)$ & 0.065 \\
\hline Serum calcium (mg/dl) & $2.65(2.54-2.68)$ & $2.65(2.54-2.67)$ & $2.63(2.6-2.68)$ & 0.63 \\
\hline Serum phosphate (mg/dl) & $1.705(1.5-1.81)$ & $1.66(1.44-1.81)$ & $1.71(1.51-1.83)$ & 0.48 \\
\hline Number of cysts ( $>10 \mathrm{~mm}$ in diameter) & $1(0-4.25)$ & $3(2-7)$ & $0(0-0)$ & $<0.001$ \\
\hline $\operatorname{TKV}\left(\mathrm{cm}^{3}\right)$ & $222.31(126.57-315.52)$ & $248.40(148.18-459.53)$ & $178.14(109.33-223.94)$ & $<0.001$ \\
\hline TKV/BSA $\left(\mathrm{cm}^{3} / \mathrm{m}^{2}\right)$ & $135.34(105.91-187.3)$ & $155.24(120.55-224.54)$ & $115.43(98.34-126.07)$ & $<0.001$ \\
\hline
\end{tabular}

ADPKD - autosomal dominant polycystic kidney disease, FGF-23 - fibroblast growth factor 23, uACR - urine albumin-creatinine ratio, eGFR - estimated glomerular filtration rate, TKV - total kidney volume, $B S A$ - body surface area; data are presented as median value and $27-75$ interquartile range

Shapiro-Wilk test. Data are presented as median value and 25-75 interquartile range. Due to distribution other than normal, comparisons of continuous variables between two different groups were performed using the Mann-Whitney test. The Spearman correlation coefficient was used to assess the correlation of variables. A $p$-value below 0.05 was considered statistically significant. STATISTICA 10.0 and PQStat v1.6.6 programs were used for statistical analysis.

\section{RESULTS}

The median serum level of FGF-23 was $27.77 \mathrm{pg} / \mathrm{ml}$ (interquartile range $12.49-134.29 \mathrm{pg} / \mathrm{ml}$ ) in children

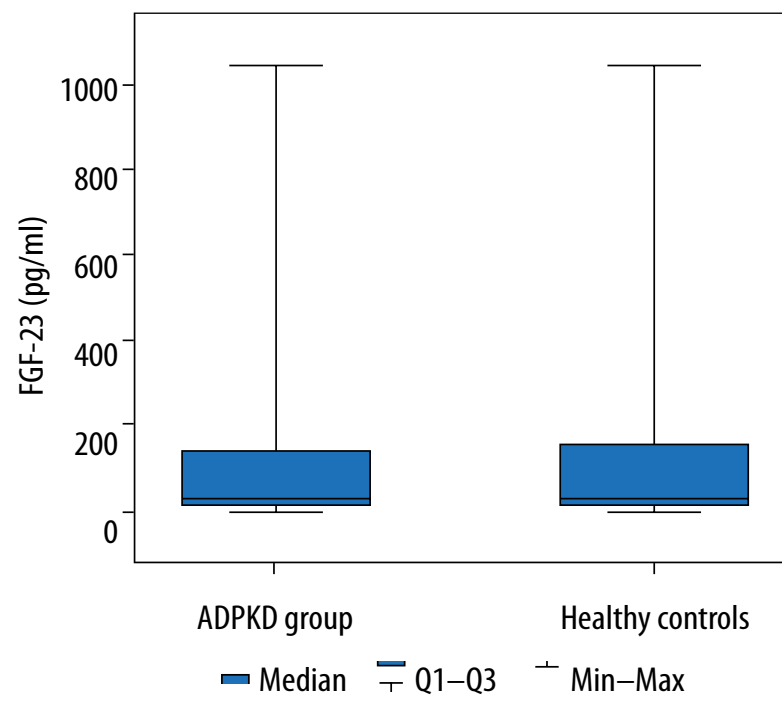

FIGURE 1. Fibroblast growth factor 23 (FGF-23) serum concentration in the study autosomal dominant polycystic kidney disease (ADPKD) group and healthy controls with ADPKD and $24.15 \mathrm{pg} / \mathrm{ml}$ (interquartile range 8.46$154.78 \mathrm{pg} / \mathrm{ml}$ ) in the healthy group (Fig. 1). The median serum $\alpha$-Klotho level was $1650 \mathrm{pg} / \mathrm{ml}$ (interquartile range $950-2580 \mathrm{pg} / \mathrm{ml}$ ) in children with ADPKD and $1440 \mathrm{pg} / \mathrm{ml}$ (interquartile range $680-1950 \mathrm{pg} / \mathrm{ml}$ ) in the healthy group (Fig. 2).

There were no differences in FGF-23 levels as well as $\alpha$-Klotho protein levels between children with ADPKD and the healthy control group. Also, no differences were detected between male and female subjects.

Both FGF-23 and $\alpha$-Klotho had a few large outlier cases; removing these cases did not change the result. There was no relation for these cases.

Children with ADPKD compared to the control group manifested a statistically significant difference in TKV (mean value $248.40 \mathrm{~cm}^{3}$ vs. $178.14 \mathrm{~cm}^{3} ; p<0.001$ ).

ADPKD patients mean cysts number was 3 , and there was a statistically significant positive correlation between the number of cysts and TKV $(p<0.001)$. There was also positive correlation between the number of cysts and the patients' age ( $R s=0.41 ; p=0.000751)$, body mass (Rs 0.38; $p=0.001731)$, and the height $(R s=0.42$; $p=0.000605)$.

Between patients with ADPKD and the control group the value of TKV/ BSA and ACR (Table 1) presented a statistically significant difference $(p<0.05)$.

The analysis showed a statistically significant positive correlation between the serum levels of FGF-23 and the serum $\alpha$-Klotho protein level $(R s=0.55 ; p=0.000002)$ (Fig. 3). Additionally, the total group of patients had a significantly positive correlation between Klotho protein levels in the serum and eGFR $(R s=0.25 ; p=0.039566)$ (Fig. 4). However, FGF-23 and Klotho protein concentra- 
tion did not show a similar correlation with ACR, TKV, TKV/BSA, body weight $(\mathrm{kg})$, height $(\mathrm{cm})$, age (months), phosphate concentration, and calcium concentration in the Spearman's rank correlation coefficient. In the healthy control group there was a significant negative correlation between Klotho protein levels and the age of children (months) $(R s=-0.45 ; p=0.033131)$. Such a relationship was not observed in the group of ADPKD patients.

The Spearman's rank correlation coefficient showed positive correlation between ACR and TKV/BSA $(R s=0.45$; $p=0.000152)$, as well as ACR and TKV $(R s=0.35$; $p=0.003349)$ and ACR and the number of cysts $(R s=0.4$; $p=0.001192$ ). In addition, there was negative correlation between the level of phosphate and TKV $(R s=-0.46$; $p=0.006852)$ in the total group of patients as well as the healthy control group ( $R s=-0.81 ; p=0.000839$ ). Such a correlation was not observed in the group of patients with ADPKD. Also, the level of phosphate concentration negatively correlated with height $(R s=-0.60$; $p=0.000159)$, weight $(R s=-0.66 ; p=0.000022)$, and age $(R s=-0.65 ; p=0.000035)$ of the children.

\section{DISCUSSION}

The main purpose of this study was the assessment of FGF-23 and Klotho protein concentration among the paediatric patients with ADPKD and in a control group of healthy children. We did not find a significant difference in the level of FGF-23 in the serum between patients and the healthy control group.

Most of the research states that the eGFR decrease is correlated with FGF-23 concentration increase in ADPKD and CKD patients in both adults [13-16] and children [8, 17-21]. The highest concentration of FGF-23 was found among patients with end-stage renal disease $[19,22]$. FGF-23 can be recognised as an independent predictor of CKD progression in children [23]. In this study we did not find any correlation between FGF-23 serum and eGFR levels. This could be due to the fact that all of the patients had normal eGFR levels. Additionally, there was no difference in the eGFR levels between ADPKD patients and healthy children. It is hard to detect the correlation between eGFR and FGF-23 serum concentration during the early stages of CKD because of the difficulty to precisely assess eGFR. In ADPKD patients the GFR threshold beyond which FGF-23 concentration increases has not been determined [24]. There are studies showing that patients with APDKD have higher serum FGF-23 levels than patients with CKD with a different aetiology [25]. Our research shows that children with ADPKD and eGFR $>90 \mathrm{ml} / \mathrm{min} / 1.73 \mathrm{~m}^{2}$ do not have elevated FGF-23 serum levels.

Our results showed that children with ADPKD had comparable Klotho protein concentrations to patients from the healthy control group. The mean serum Klotho values were similar to the results achieved by

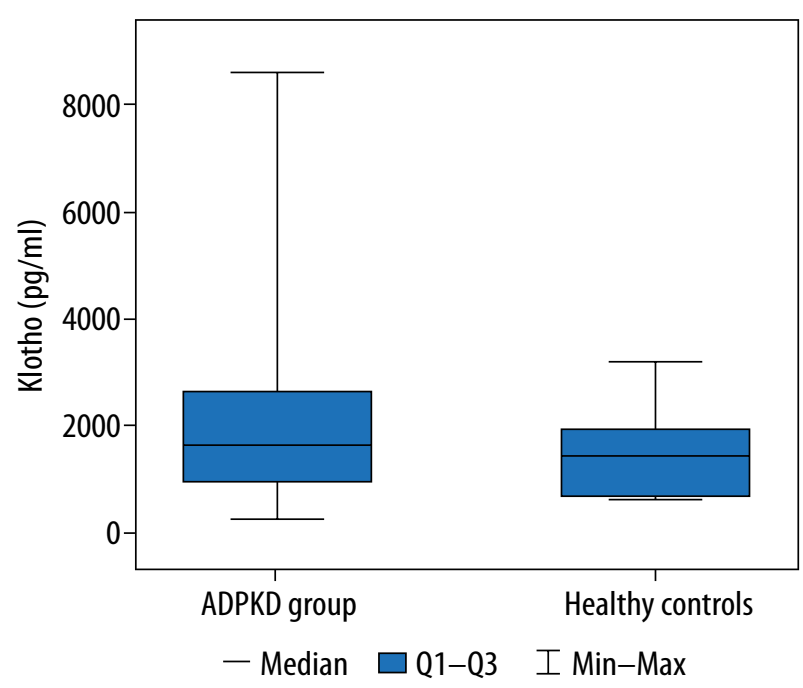

FIGURE 2. Klotho serum concentration in the study autosomal dominant polycystic kidney disease (ADPKD) group and healthy controls

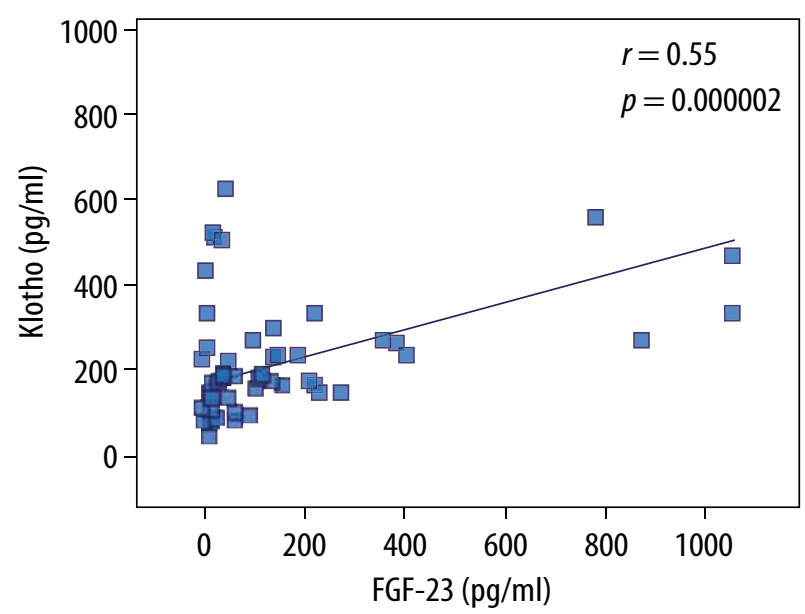

FIGURE 3. Spearman positive correlation between the serum levels of fibroblast growth factor 23 (FGF-23) and Klotho concentrations in the study group

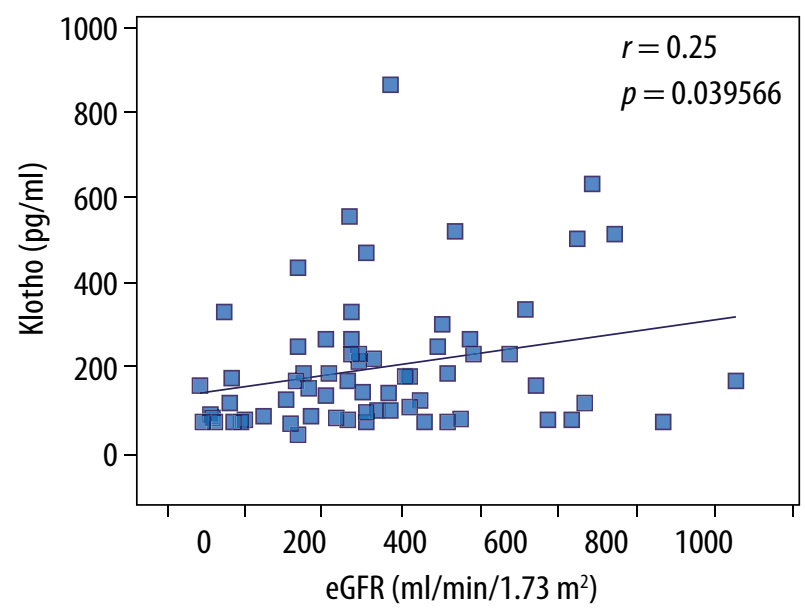

FIGURE 4. Positive correlation between serum levels of Klotho and estimated glomerular filtration rate (eGFR) in the study group calculated using the Spearman's rank correlation coefficient 
Gkentzi et al. during studies conducted on a group of 159 healthy children [25].

Klotho protein concentration increased as the eGFR increased, which was observed in the total cohort group. Information about Klotho protein fluctuations during CKD progression are disparate [13-19, 26-29]. Most of the available research says that adult patients with ADPKD experience serum Klotho concentration decrease with the progression of CKD [13-15, 26, 27]; the same can also be observed in children [17-19]. According to Akiyama et al., Klotho concentration is significantly lower in patients with CKD caused by ADPKD than in patients with CKD of a different aetiology [30]. This is explained by abnormalities localised in renal tubules that occur during ADPKD [25]. On the other hand, Sari et al. suggest autonomic Klotho protein production as the cause of its increased concentration during ADPKD. It could be connected with excessive tubule cell proliferation and cyst growth, and thus increased secretion of some substances [16]. A parallel situation has been suggested in which erythropoietin accumulates in renal cysts of patients suffering from ADPKD [31]. Both EPO as well as Klotho protein could be produced by the epithelium of the proximal tubule cells [32].

Our study confirms that children with ADPKD have larger kidney volume than healthy children. We did not observe any correlation between total kidney volume and Klotho protein or FGF-23 concentration, which is in contradiction to the above-mentioned hypotheses. However, it is possible that in some ADPKD patients there could be "productive cysts" that can produce excessive Klotho protein, for example because of the existence of extra tubule cells, and cysts without them in other patients. It could be the reason for our large number of outlier cases. Further histopathological studies are needed.

With the kidney volume increase, ACR values are also increased, and this value was higher among children suffering from ADPKD compared to the healthy ones. It could be caused by kidney damage due to the ADPKD. The ACR value was not correlated with Klotho protein concentration or with FGF-23 concentration. In that respect ACR seems to be a better early-stage kidney damage marker compared to Klotho protein or FGF-23.

ADPKD children at early stages of chronic kidney disease (stage 1) do not show changes in the FGF-23Klotho axis, which could be dependent rather on further eGFR decrease than on increase of kidney volume or cyst number.

Our study revealed that Klotho concentration decreases depending on the age of healthy children. The group of patients suffering from ADPKD did not exhibit such a dependency. Similar correlation was found in a group of healthy adults [33] and children with CKD of a varied aetiology [18]. According to several sources, both FGF-23 and Klotho do not correlate with age [25].
During the research it was observed that with the increase of FGF-23 concentration Klotho protein concentration also increased. Scientists from Greece also obtained the same results during their research on healthy children [25]. Similar results were also published by Sari et al. [16]. In our research we observed a positive correlation between FGF-23 and Klotho concentration both in children with ADPKD and the children from the healthy control group. Other publications regarding CKD present different results $[18,34]$, or in some cases no correlation was observed [28, 29, 33, 35-37]. It would seem that because Klotho is a co-receptor for FGF-23 an increase of FGF-23 should decrease the level of Klotho [19]. Because the ADPKD patients in our study did not have elevated FGF-23 concentration and did not have decreased glomerular filtration, no such correlation was observed.

In the study, no disorders in calcium-phosphate metabolism in children with ADPKD were observed. Both calcium and phosphate concentrations were not correlated with FGF-23 or Klotho concentrations. Data regarding the relation between FGF-23 and Klotho protein with calcium and phosphate concentration are contradictory $[8,18-21,25,38-40]$.

The discovery of FGF-23 and Klotho gave hope for its use as a kidney disease progression marker. However, the literature on this topic is scarce. Most of the authors studied changes in Klotho and FGF-23 changes in CKD patients including many other causes of disease than ADPKD, which can blur the view of the matter.

\section{CONCLUSIONS}

According to the study, FGF-23 and Klotho concentration does not differ significantly between children suffering from ADPKD and the control group. At this stage of the disease, its concentration is not related to the classical markers of progression of the disease. Our study had a number of limitations, including its cross-sectional design and low number of children in the ADPKD group. This is clearly the result of the rather rare diagnosis of this disease before 18 years of age. Hence, further research on this topic requires a larger study group in which more variables should be taken into consideration.

\section{DISCLOSURE}

The authors declare no conflict of interest.

\section{REFERENCES}

1. Cadnapaphornchai MA. Autosomal dominant polycystic kidney disease in children. Curr Opin Pediatr 2015; 27: 193-200.

2. Pavik I, Jaeger P, Kistler AD, et al. Patients with autosomal dominant polycystic kidney disease have elevated fibroblast growth factor 23 levels and a renal leak of phosphate. Kidney Int 2011; 79: 234-240. 
3. Seeman T, Dušek J, Vondrichová, et al. Ambulatory blood pressure correlates with renal volume and number of renal cysts in children with autosomal dominant polycystic kidney disease. Blood Press Monit 2003; 8: 107-110.

4. Cadnapaphornchai MA, McFann K, Strain JD, et al. Increased left ventricular mass in children with autosomal dominant polycystic kidney disease and borderline hypertension. Kidney Int 2008; 74: 1192-1196.

5. Wolf M. Update on fibroblast growth factor 23 in chronic kidney disease. Kidney Int 2012; 82: 737-747.

6. Shimada T, Hasegawa H, Yamazaki Y, et al. FGF-23 is a potent regulator of vitamin D metabolism and phosphate homeostasis. J Bone Miner Res 2004; 19: 429-435.

7. Małyszko J. Klotho protein and chronic kidney disease [Białko Klotho a przewlekła choroba nerek]. Forum Nefrol 2009; 2: 69-73.

8. Liu D, Alvarez-Elías AC, Wile B, et al. Deviations from the expected relationship between serum FGF23 and other markers in children with CKD: a cross-sectional study. BMC Nephrology 2017; 18: 204.

9. Fick-Brosnahan GM, Tran ZV, Johnson AM, et al. Progression of autosomal-dominant polycystic kidney disease in children. Kidney Int 2001; 39: 1654-1662.

10. Chapman AB, Devuyst O, Eckardt KU, et al. Autosomal-dominant polycystic kidney disease (ADPKD): executive summary from a Kidney Disease: Improving Global Outcomes (KDIGO) Controversies Conference. Kidney Int 2015; 88: 17-27.

11. Ix JH, Shlipak MG, Wassel CL, Whooley MA. Fibroblast growth factor-23 and early decrements in kidney function: the Heart and Soul Study. Nephrol Dial Transplant 2010; 25: 993.

12. Ravine D, Sheffield LJ, Danks DM, et al. Evaluation of ultrasonographic diagnostic criteria for autosomal dominant polycystic kidney disease 1. Lancet 1994; 343: 824-827.

13. Gutierrez O, Isakova $\mathrm{T}$, Rhee E, et al. Fibroblast Growth Factor- 23 Mitigates Hyperphosphatemia but Accentuates Calcitriol Deficiency in Chronic Kidney Disease. J Am Soc Nephrol 2005; 16: 2205-2215.

14. Koh N, Fujimori T, Nishiguchi S, et al. Severely Reduced Production of Klotho in Human Chronic Renal Failure Kidney. Biochem Biophys Res Commun 2001; 280: 1015-1020.

15. Salwa I, Rashed L. Serum fibroblast growth factor-23 levels in chronic haemodialysis patients. Int Urol Nephrol 2009; 41: 163-169.

16. Sari F, Inci A, Dolu S, et al. High serum soluble $\alpha$-Klotho levels in patients with autosomal dominant polycystic kidney disease. J Investig Med 2017; 65: 358-362.

17. Lindblad YT, Olauson H, Vavilis G, et al. The FGF23-Klotho axis and cardiac tissue Doppler imaging in pediatric chronic kidney disease - a prospective cohort study. Pediatr Nephrol 2018; 33: 147-157.

18. Wan M, Smith C, Shah V, et al. Fibroblast growth factor 23 and soluble klotho in children with chronic kidney disease. Nephrol Dial Transplant. 2013; 28: 153-161.

19. Sawires HK, Essam RM, Morgan MF, Mahmoud RA. Serum Klotho: Relation to Fibroblast Growth Factor-23 and Other Regulators of Phosphate Metabolism in Children with Chronic Kidney Disease. Nephron 2015; 129: 293-299.

20. Wesseling-Perry K, Tsai EW, Ettenger RB, et al. Mineral abnormalities and long-term graft function in pediatric renal transplant recipients: a role for FGF-23? Nephrol Dial Transplant 2011; 26: 3779-3784.

21. Bacchetta J, Dubourg L, Harambat J, et al. The Influence of Glomerular Filtration Rate and Age on Fibroblast Growth Factor 23 Serum Levels in Pediatric Chronic Kidney Disease. J Clin Endocrinol Metab 2010; 95: 1741-1748.

22. Viaene L, Bammens B, Meijers BKI, et al. Residual renal function is an independent determinant of serum FGF-23 levels in dialysis patients. Nephrol Dial Transplant 2012; 27: 2017-2022.
23. Portale AA, Wolf MS, Messinger S, et al. Fibroblast Growth Factor 23 and Risk of CKD Progression in Children. Clin J Am Soc Nephrol 2016; 11: 1989-1998.

24. Bożentowicz-Wikarek M, Kocełak P, Chudek J. FGF-23 as a marker of impaired glomerular filtration rate [FGF-23 jako marker upośledzenia filtracji kłębuszkowej]. Nephrol Dial Pol 2011; 15: 53-56.

25. Gkentzi D, Efthymiadou A, Kritikou D, Chrysis D. Fibroblast growth factor 23 and Klotho serum levels in healthy children. Bone 2014; 66: 8-14.

26. Pavik I, Jaeger P, Ebner L, et al. Secreted Klotho and FGF23 in chronic kidney disease Stage 1 to 5 : a sequence suggested from a cross-sectional study. Nephrol Dial Transplant 2013; 28: 352-359.

27. Silva AP, Mendes F, Pereira L, et al. Klotho levels: association with insulin resistance and albumin-to-creatinine ratio in type 2 diabetic patients. Int Urol Nephrol 2017; 49: 1809-1814.

28. Seiler S, Wen M, Roth HJ, et al. Plasma Klotho is not related to kidney function and does not predict adverse outcome in patients with chronic kidney disease. Kidney Int 2012; 83: 121-128.

29. Sugiura H, Tsuchiya K, Nitta K. Circulating levels of soluble $\alpha$-Klotho in patients with chronic kidney disease. Clin Exp Nephrol 2011; 15: 795-796.

30. Akiyama K, Mochizuki T, Kataoka H, et al. Fibroblast growth factor 23 and soluble Klotho in patients with autosomal dominant polycystic kidney disease. Nephrology 2017; 22: 848-853.

31. Eckardt KU, Möllmann M, Neumann R, et al. Erythropoietin in polycystic kidneys. J Clin Invest 1989; 84: 1160-1166.

32. Hu MC, Shi M, Zhang J, et al. Klotho: a novel phosphaturic substance acting as an autocrine enzyme in the renal proximal tubule. FASEB J 2010; 24: 3438-3450.

33. Yamazaki Y, Imura A, Urakawa I, et al. Establishment of sandwich ELISA for soluble alpha-Klotho measurement: Age-dependent change of soluble alpha-Klotho levels in healthy subjects. Biochem Biophys Res Commun 2010; 398: 513-518.

34. Shibata K, Fujita S, Morita, et al. Association between circulating fibroblast growth factor 23, $\alpha$-Klotho, and the left ventricular ejection fraction and left ventricular mass in cardiology inpatients. PLoS One 2013; 8: e73184.

35. Pavik I, Jaeger P, Ebner L, et al. Soluble Klotho and autosomal dominant polycystic kidney disease. Clin J Am Soc Nephrol 2012; 7: 248-257.

36. Devaraj S, Syed B, Chien A, Jialal I. Validation of an immunoassay for soluble Klotho protein: decreased levels in diabetes and increased levels in chronic kidney disease. Am J Clin Pathol 2012; 137: 479-485.

37. Akimoto T, Shiizaki K, Sugase T, et al. The relationship between the soluble Klotho protein and the residual renal function among peritoneal dialysis patients. Clin Exp Nephrol 2012; 16: 442-447.

38. Wesseling-Perry K, Pereira RC, Wang H, et al. Relationship between plasma fibroblast growth factor-23 concentration and bone mineralization in children with renal failure on peritoneal dialysis. J Clin Endocrinol Metab 2009; 94: 511-517.

39. Van Husen M, Fischer AK, Lehnhardt A, et al. Fibroblast growth factor 23 and bone metabolism in children with chronic kidney disease. Kidney Int 2010; 78: 200-206.

40. Bhan I, Shah A, Holmes J, et al. Post-transplant hypophosphatemia: tertiary 'hyper-phosphatoninism’? Kidney Int 2006; 70: 1486-1494. 